\title{
The revolution in Microscopy - Simple to electron
}

\section{Amal Kumar Mondal ${ }^{1}$ and Sanjukta Mondal Parui ${ }^{2}$}

${ }^{1}$ Plant Taxonomy, Systematics and Molecular Taxonomy Laboratory, UGC-DRS-SAP Department, Department of Botany \& Forestry, Vidyasagar University, Midnapore-72112, West Bengal, India.

2Post Graduate Department of Zoology, Section Biochemistry, Lady Brabourne College, Kolkata-700 017, West Bengal, India.

Received: 4/9/2018; Accepted: 4/28/2018

Abstract: Single cell to multiple cells, simple morphology to ultrastructural studies, Biological sciences to Nano Sciences and to some extent medical sciences, has fully or partly depended on Microscopic studies. Without Leeuwenkoek's discovery we can't imagine our latest development in Research. Finally, in $21^{\text {st }}$ Centuary latest discovery i.e. foldscope microscopy with low cost, easily handle for our tiny school to field scientists.

Key words: Revolution, Microscopy, Simple, Bright Field Microscopy (BFM), Dark Field Microscopy (DFM), Phase Contrast Microscopy (PCM), Fluorescence Microscopy (FM), Polarized Light Microscope (PLM), SEM, TEM, Confocal Scanning Laser Microscopy (CSLM) and Foldscope Microscope (FM).

\section{Introduction}

There was a time when man used to ignore things we couldn't see. Lots of things are invisible, but that doesn't mean they're not there. Yet Scientists knew it from the 17 th century that the insides of all living beings are made up of tiny cells. Man has long wanted to see the invisible, venture into the impossible and discover the various mysteries of life. This has led to the discovery of microscopes. It's quite fascinating to imagine our eyes to be as powerful as microscopes so that we can even see all the germs crawling about on our hands. The invention of microscopes and modern science has opened up a whole new dimension in science. We know now that there's a whole lot happening on the microscopic scale that can help us to live our lives more effectively. Microscope is the combination of two words; "micro" meaning small and "scope" meaning view. By using microscopes, scientists have been able to discover the existence of microorganisms, study the structure of cells, and see the smallest parts of plants, animals, and fungi. Microscope may be defined as an optical instrument consisting of a lens or combination of lenses for making an enlarged or magnified image of a minute object. The simplest microscope is a magnifying glass made from a single convex lens, which typically magnifies by about 5-10 times. Since their original invention, microscopes have undergone a revolution and gone beyond the simple visible light refracting lenses. Electrons, $\mathrm{x}-$ rays, and infrared rays are used by far more sophisticated (and expensive) microscopes to detect even smaller and smaller structures. Scanning electron microscopes are able to resolve viruses, which are far smaller than any cell.

\section{${ }^{*}$ Corresponding Author:}

Prof. Amal Kumar Mondal, FLS, FIAAT

Professor of Botany \& Coordinator UGC-DRS-SAP \& DBT-BOOST-WB Funded

Department of Botany \& Forestry,

Plant Taxonomy, Biosystematics and Molecular Taxonomy Laboratory,

Vidyasagar University, Midnapore-721 102, West Bengal, India.

E-mail: $\underline{\text { amalcaebotvu@gmail.com, akmondal@mail.vidyasagar.ac.in }}$
Surprisingly the first microscope was constructed by a Dutch scientist Antony van Leeuwenhoek (16321723) who was in fact an ordinary public official andhad a hobby of grinding lenses and make microscopic observations. $\mathrm{He}$ is said to have constructed nearly 400 simple microscopes which basically consisted of a single biconvex lens. Some of these microscopes had a considerable magnifying power up to 200 times. One of Leeuwenhoek's microscopes is shown in Fig. 1. In this microscope the eye was applied close to the lens on one side and the object was mounted on the needle-like screw point on the opposite side of the lens.

The early microscopes, like Leeuwenhoek's, were called simple because they only had one lens and had limitations to the amount of magnification no matter how they were constructed. However, the invention of the compound microscope helped to advance the field of microbiology light years ahead of where it had been only just a few years earlier. A second lens was added to magnify the image of the first lens. Modern compound light microscopes, under optimal conditions, can magnify an object $1000 \mathrm{X}$ to $2000 \mathrm{X}$ times. The specimen has to be sufficiently thin and bright for the microscope light to pass through and it is mounted on a glass slide. In a Compound Microscope, the light is transmitted and focused by mirror and condenser which illuminate the object or specimen. The refracted light is then collected by an objective where primary image of the object is formed which is real, inverted and enlarged. The eyepiece then further magnifies this primary image into a final virtual, erect and enlarged image. Although compound microscopes have two eye 
pieces, they are however not capable of producing a three dimensional or stereoscopic view. This is because each one of the eyes receives the same image from the objective and the light beam is simply split in two. Robert Hook (1635-1703), an English scientist developed a compound microscope by using two lenses for achieving greater magnification. In Hooke's microscope (Fig.2) the object to be seen was placed on the stage below and light from an oil flame was thrown on it by means of a concave mirror. The ordinary compound microscope (Fig.3) of today is a greatly improved design of the original Hook's microscope.

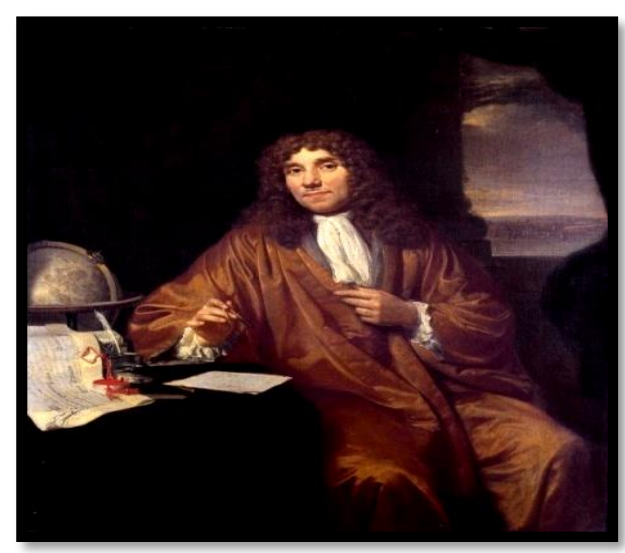

Fig.1a: Antony van Leeuwenhoek (Courtesy: Wikipedia)

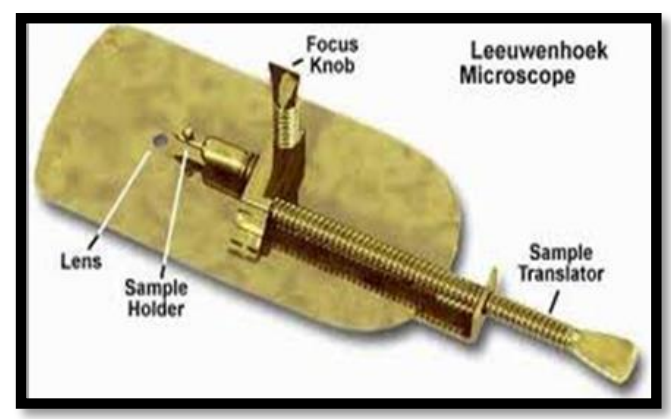

Fig.1b: Leeuwenhoek's microscopes (Courtesy: Wikipedia).

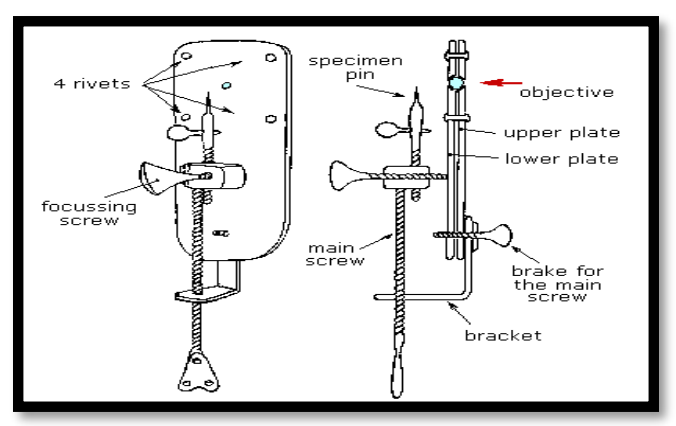

Figure 1 - Diagram of the microscope constructed by Antoni van Leeuwenhoek in the XVII century (Courtesy: Wikipedia)

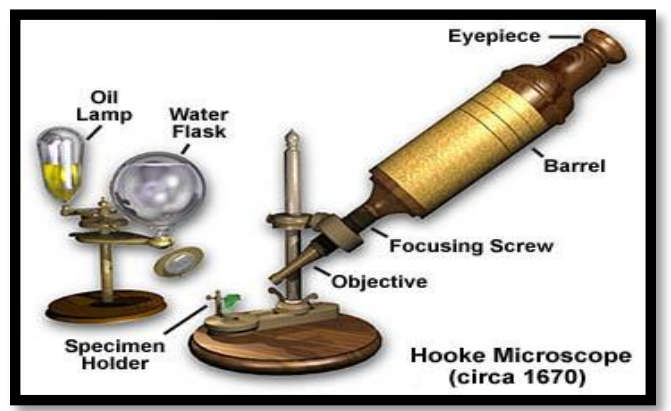

Fig.2: Hooke’s microscope

(Courtesy: Wikipedia).

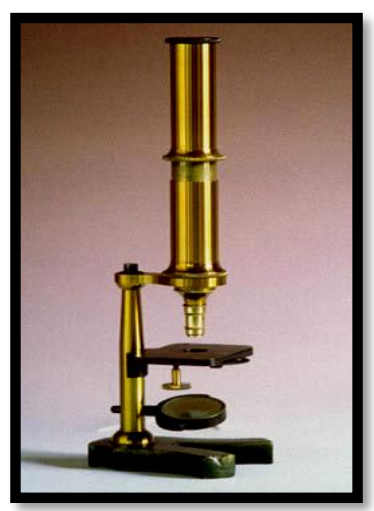

Fig. 3: An ordinary simple compound microscope (Courtesy: Wikipedia)

Stereo microscopes are frequently used for a truly stereoscopic view of larger, opaque specimens. Unlike compound microscopes, the image delivered to each eye is slightly different thus giving the stereoscopic view. However, they generally do not magnify as much as compound microscopes (around 40x-70x maximum). Neither do they require elaborate sample preparation.

The invention of the electron microscope added further to the unknown facts about cells. It can give a magnification to over 200,000 times as against the ordinary compound microscope which magnifies an object up to a maximum of about 2,000 times. The ordinary compound microscope uses light which is bent by glass lenses to magnify the image while the electron microscope uses beams of electrons which are bent by magnets.

The efficiency of a microscope depends not only upon magnification but also resolution i.e. the ability to distinguish two adjacent points as separate. Although magnification can be increased virtually without limit, resolution cannot be as it depends upon the physical properties of light. Thus the limit of what we can see with a microscope is ultimately defined by its resolution and not magnification. The highest resolution possible in a compound light microscope is about $0.2 \mu \mathrm{m}$ [200 nanometers]. That means that two objects closer together than $0.2 \mu \mathrm{m}$ are not resolvable as distinct and separate. Using an 
electron microscope improves the resolution by about 1000-fold over that of the light microscope. Resolving power is a function of the wavelength of light used and an innate property of the objective lens known as its numerical aperture (a measure of light gathering ability). Lenses with higher magnification usually have higher numerical apertures. The diameter of the smallest resolvable object is equal to $0.5 \lambda /$ numerical aperture, where $\lambda$ is the wavelength of light used. Thus, resolution is greatest when blue light is used to illuminate a specimen and the objective that is used has a very high numerical aperture.

Light Microscopes are the simplest of all microscopes in which lenses which, magnify the image of a cell, are use to bend and focus light rays to produce enlarged images of small objects (Fig. 4). They are of great importance in the study of morphology of microorganisms, intracellular structures of cells, blood smears, biomolecules, measurement of size, biological activity, such as the uptake of food, cell division and movement etc. One of the biggest advantage of using a light microscope is the ability to observe living cells. It is even possible to use in-vivo staining techniques to observe the uptake of colored pigments by the cells. This is not possible by using an electron microscope, as the specimen there is dead as it has been completely dehydrated and has to be fixed. Because of their low costs these optical or light microscopes are widely used in different areas particularly the education and the medical sector.

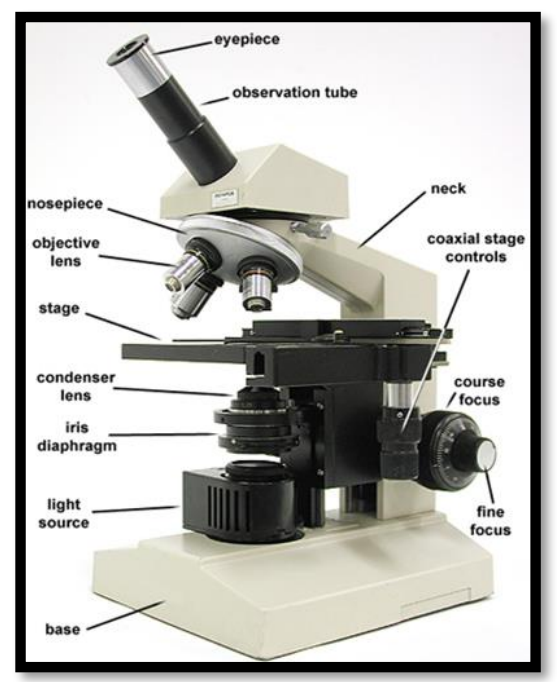

Fig. 4a: Light Microscopy (LM).

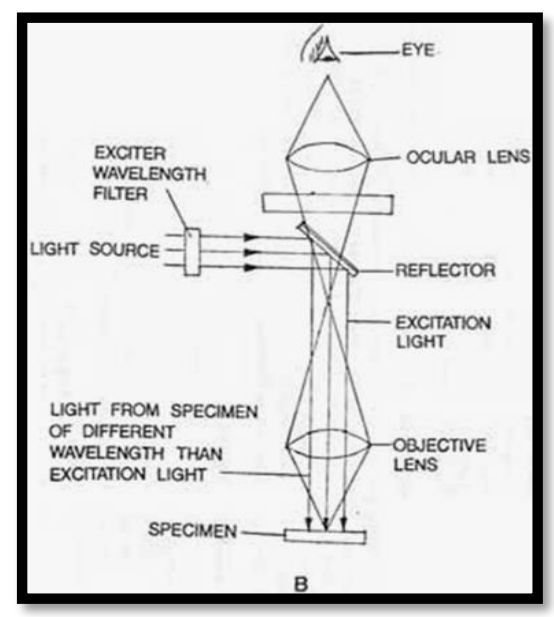

Fig.4b: Diagrammatic representation of Light Microscopy (LM).

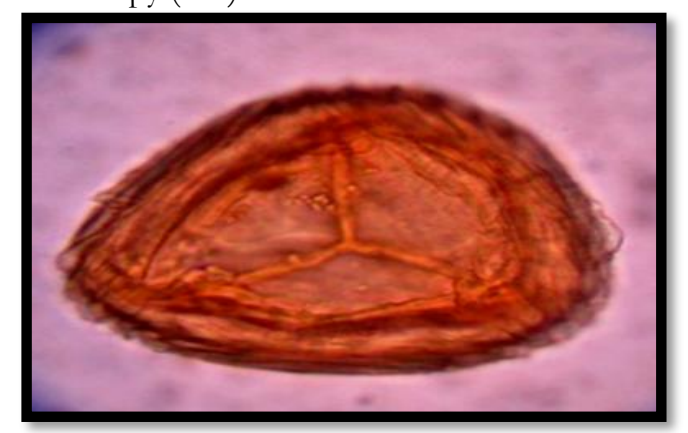

Fig. 4c: Spore photograph under Light Microscopy (LM).

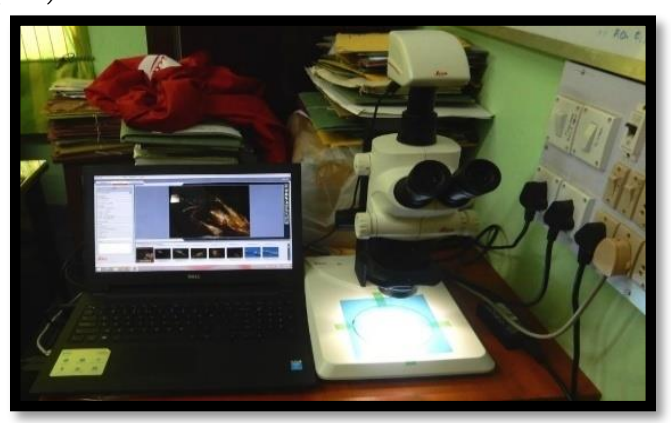

Fig. 4d: Stereo Zoom Microscope (SZM) in Plant Taxonomy, Biosystematics and Molecular Taxonomy Laboratory, Department of Botany \& Forestry, VU funded by UGC-MRP.

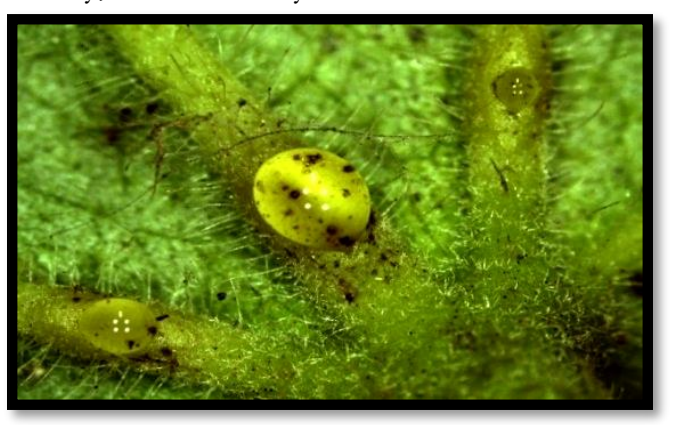

Fig.4e: Extrafloral nectar under Stereo Zoom Microscope (Urena lobata) 


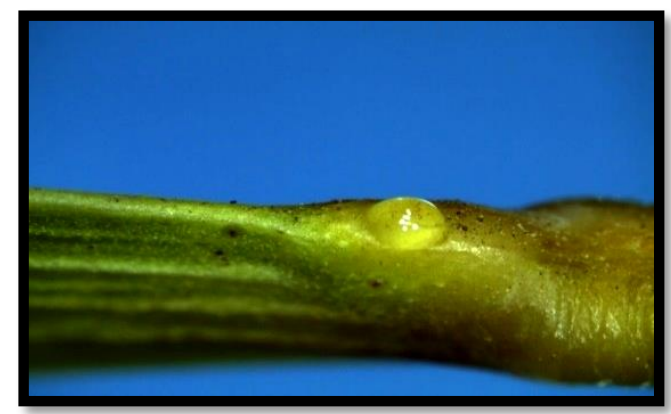

Fig. 4f: Extrafloral nectar under Stereo Zoom Microscope (SZM) [Acacia auriculiformes, Mimosaceae]

The light microscope uses sunlight or artificial light. There are different types of light microscopes that are used:

- $\quad$ Bright Field Microscopy (BFM);

- $\quad$ Dark Field Microscopy (DFM);

- $\quad$ Phase Contrast Microscopy (PCM);

- $\quad$ Fluorescence Microscopy (FM);

- Polarized Light Microscope (PLM).

In Bright Field Microscopy, the microscopic field (the area observed) is brightly lighted and the microorganisms appear dark because they absorb some of the light. Ordinarily microorganisms do not absorb light but staining them with a dye greatly increases their light absorbing ability resulting in greater contrast and color differentiation. The microscopes of this type provide magnification of about X1000 to X2000 above which the image becomes fuzzy.

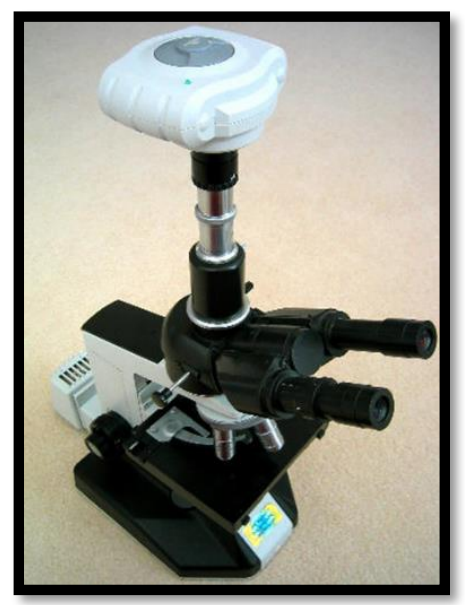

Fig.5a: Dark Field Microscopy (DFM)

In Dark Field microscopy the specimens appear brilliantly illuminated against a dark background. This is achieved by fitting the light microscope with a special type of condenser that transmits a hollow cone of light from the source of illumination. Most of this light directed through the condenser does not enter the objective. Hence the microscopes field appears dark. However, when the microorganisms are present in the transparent medium, some of the light rays will be scattered (diffracted) which will enter the objective and reach the eye. Thus the cells will appear bright in an otherwise dark microscopic field. This technique is valuable for examination of unstained microorganisms suspended in fluid (wetmount and hanging drop preparation).

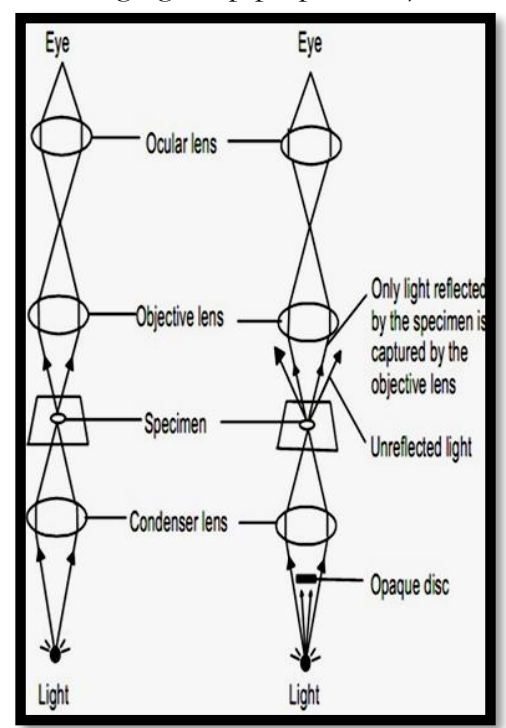

Fig.5b: Diagrammatic structure of Dark Field microscopy (DFM).

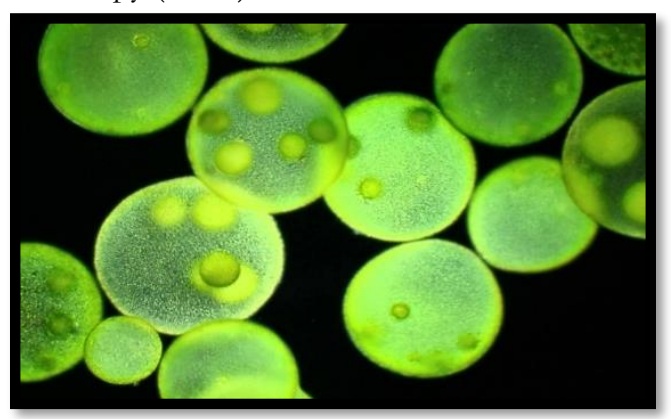

Fig. 5c: Cholorophycean algae Volvox under Dark Field Microscope (DFM).

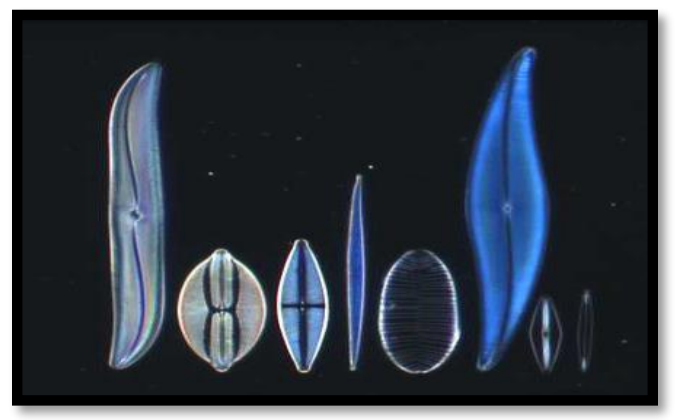

Fig. 5d: Different types of diatoms (Bassilariphyceae) under Dark Field Microscope (DFM).

Phase Contrast Microscopy helpsto improve contrast differences between cells and the surrounding medium, making it possible to see cells without staining them. It is very useful for studying the difference in cells and their structures which is 
not possible by other microscopic methods. It is widely employed in research applications because it can be used to observe wet-mount (living) preparations. Staining, on the other hand, although a widely used procedure in light microscopy, generally kills cells and can distort their features. In this technique, the conventional light microscope is fitted with a phase-contrast objective and a phase contrast condenser (Fig. 6). This optical system helps us to distinguish unstained structures within a cell which differ only slightly in their refractive indices or thicknesses. The principle behind this technique is that when light passes through one material into another material which slightly differs in refractive index and or thickness, it will undergo a change in phase. These differences in phase are translated into variations in brightness of the structures i.e. amplified by a special ring in the objective lens which are detectable by the eye.

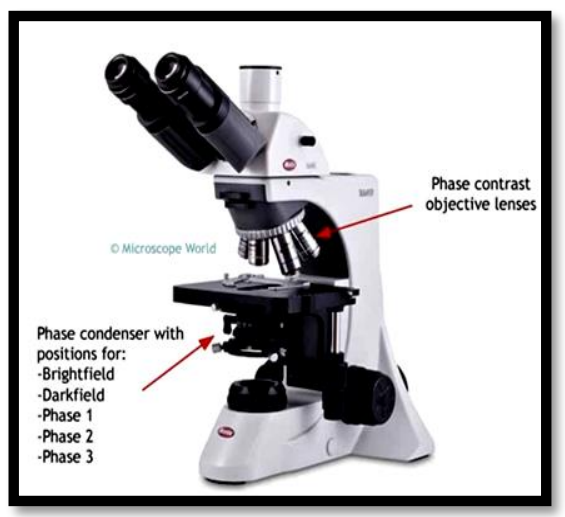

Fig. 6a: Phase Contrast Microscopy (PCM).

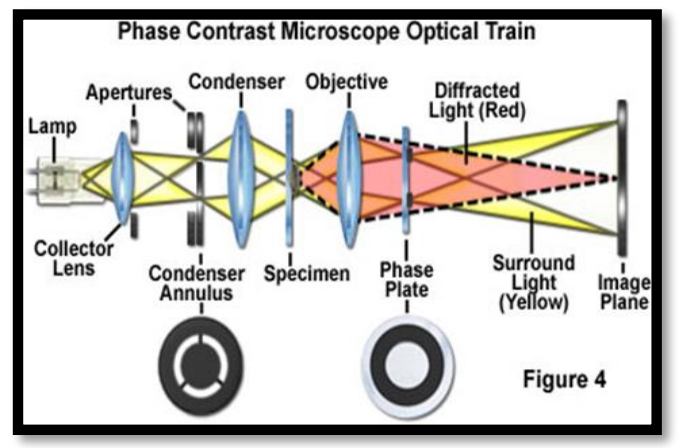

Fig. 6b: Diagrammatic structure of Phase Contrast Microscopy (PHC).

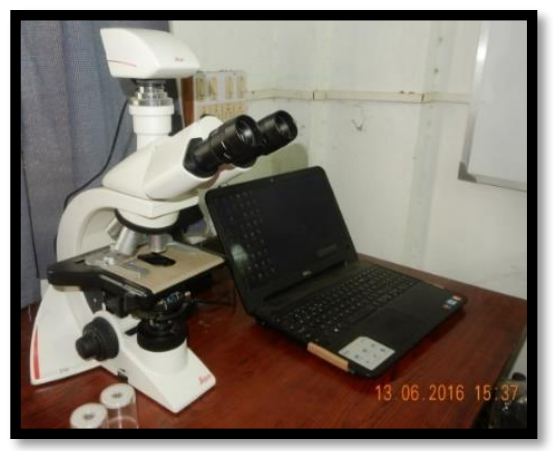

Fig. 6c: Phase Contrast Microscope (PCM).
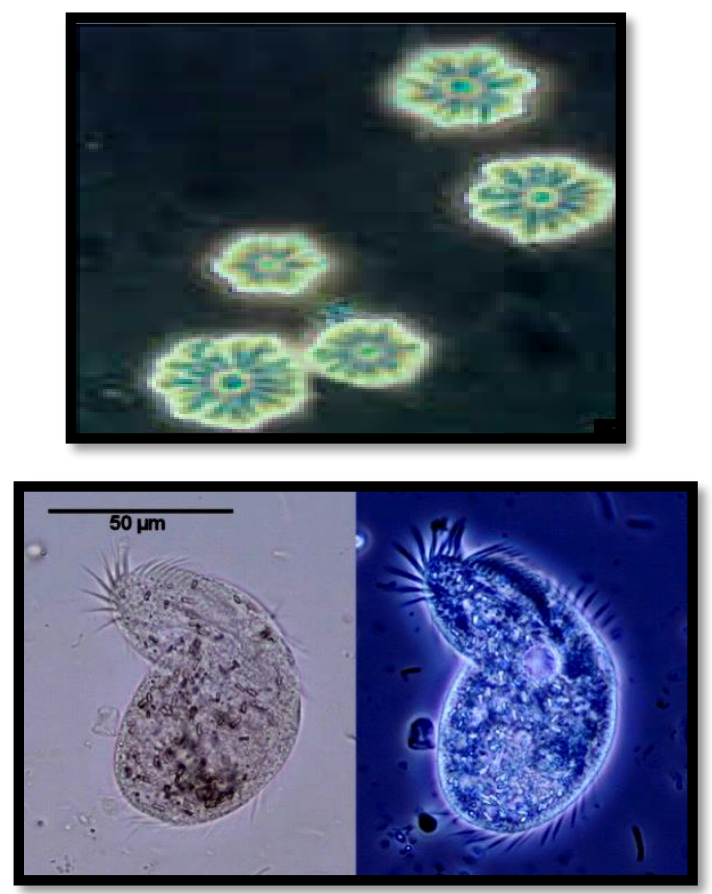

Fig. 6d, e \& f: Photographs under Phase Contrast Microscopy (PCM)

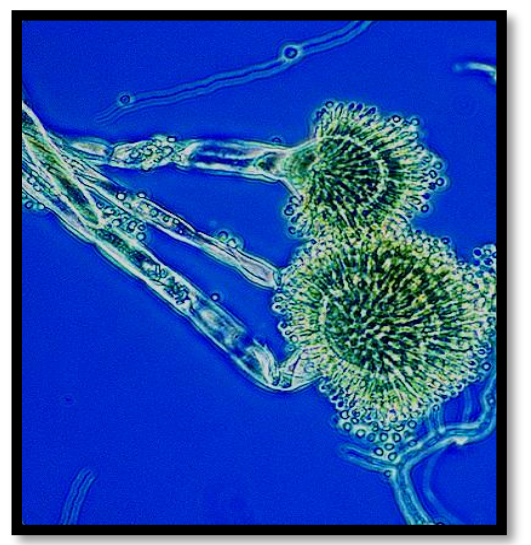

Fig. 6g: Photographs of Ascomycetes fungi Aspergillus under Phase Contrast Microscopy (PCM).

Differential Interference Contrast Microscopy (DIC) is another form of light microsopy useful for observing unstained cells. It has the ability to generate images that reveal internal cells structures that are less apparent or even invisible by bright field techniques. It employs a polarizerto produce planepolarized light (Fig. 7). The polarized light passes through a prism that generates two distinct beams which traverse the specimen and enter the objective lens where the two beams are recombined into one. Because of slight differences in refractive index of the substances through which the beam passes, the combined beams are not totally in phase but instead create an interference effect. This effect intensifies subtle differences in cell structure. Thus by DIC microscopy, things like the nucleus of eukaryotic cells, spores, vacuoles, granules, and the like attain a pseudo-three-dimensional appearance. 


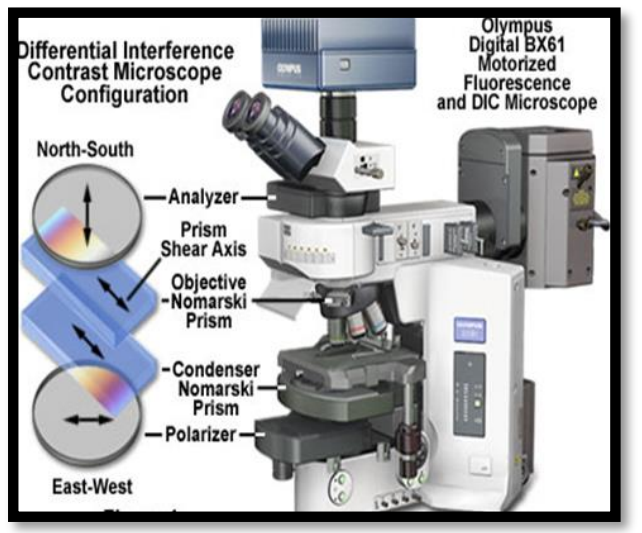

Fig. 7a: Differential Interference Contrast Microscopy (ICM).

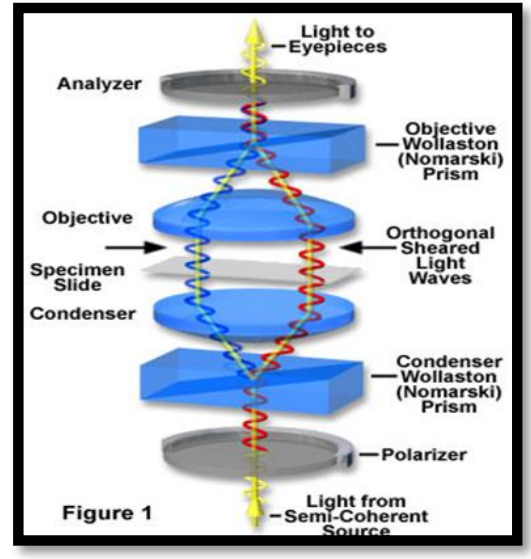

Fig. 7b: Diagrammatic representation of Interference Contrast Microscopy (ICM).

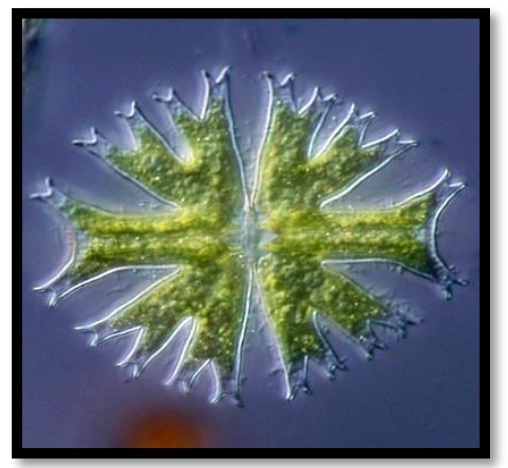

Fig. 7c: Photographs under Differential Interference Contrast Microscopy (DICM): Micrasterias sp under the Order Conjugales.

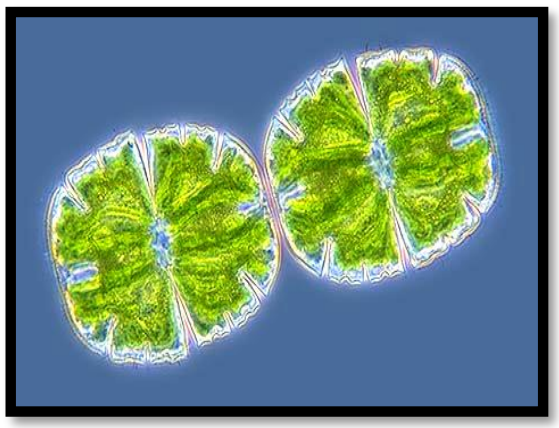

Fig. 7d: Photographs under Differential Interference Contrast Microscopy (DICM): During
Conguation of Cosmeriumi sp under the Order: Conjugales.

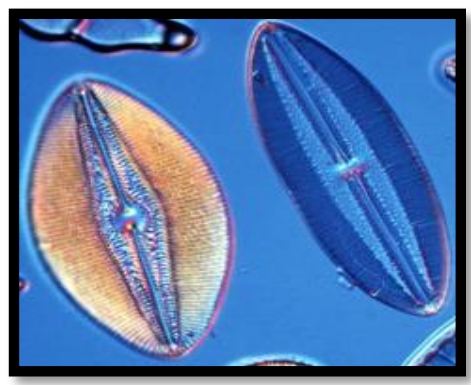

Fig. 7e: Photographs under Differential Interference Contrast Microscopy (e: Diatoms (Bassiliophyceae).
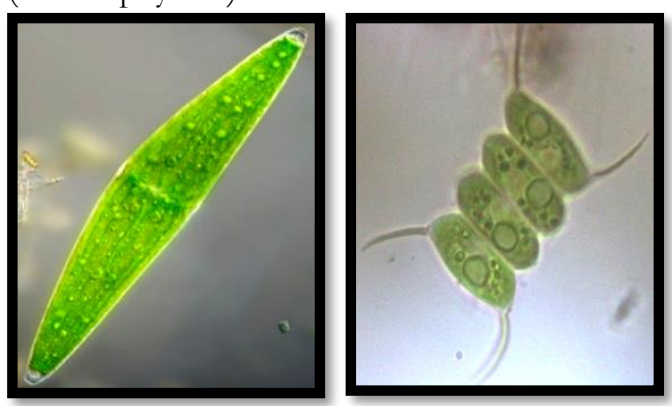

Fig. 7 f $\&$ g: Photographs under Differential Interference Contrast Microscopy f: Closterium sp under the Order Conjugales and Scenedesmus quadricauda under Chlorophyceae: Chlorococcales: Scenedesmaceae.

Fluorescence Microscopy (FM) is another type of light microscopyin which the specimens are stained with a fluorescent dye and then illuminated with blue light (Fig. 8). The blue light is absorbed and green light emitted by the dye. The dye absorbs blue light and emits light of a longer wavelength and a lesser energy content and hence fluorescence.

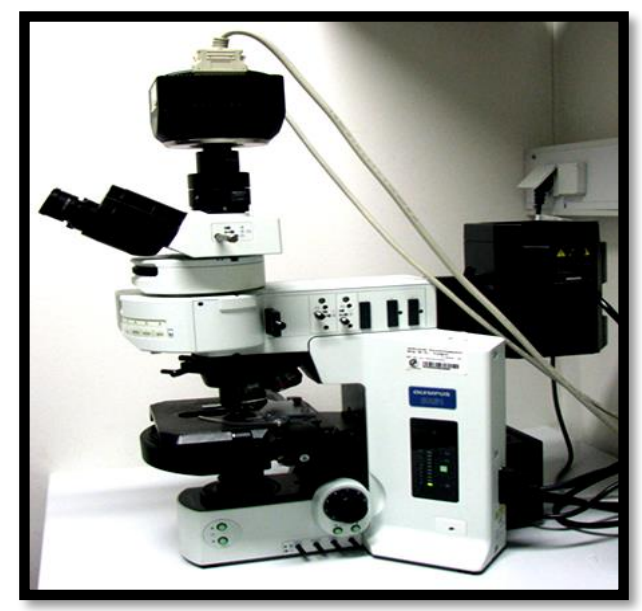

Fig. 8a: Fluorescence Microscopy (FM), University Instrumentation Centre (USIC), Vidyasagar University. 


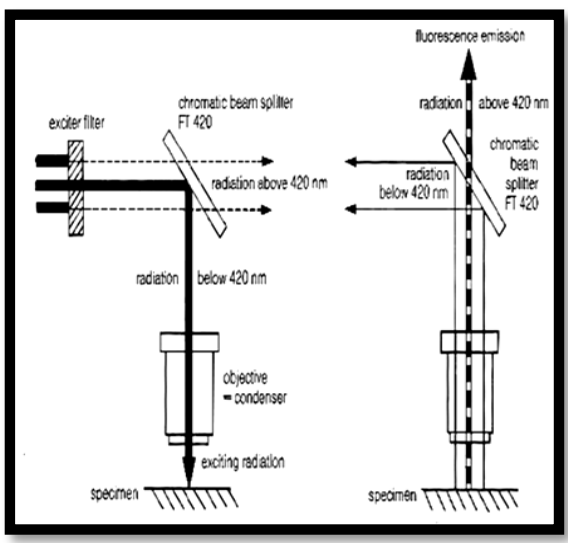

Fig. 8b: Diagrammatic structure of Fluorescence Microscopy (FM).

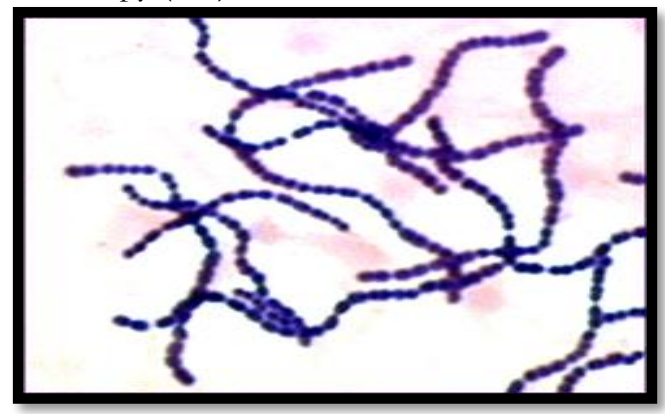

Fig. 8c: Nostoc under Fluorescence Microscopy

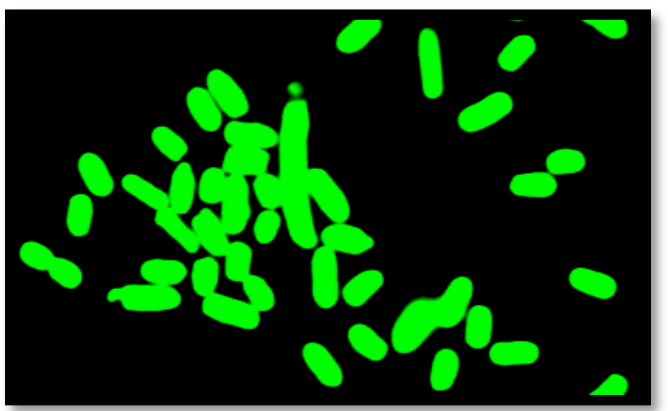

Fig. 8d: Bacteria under Fluorescence Microscopy $(\mathrm{FM})$

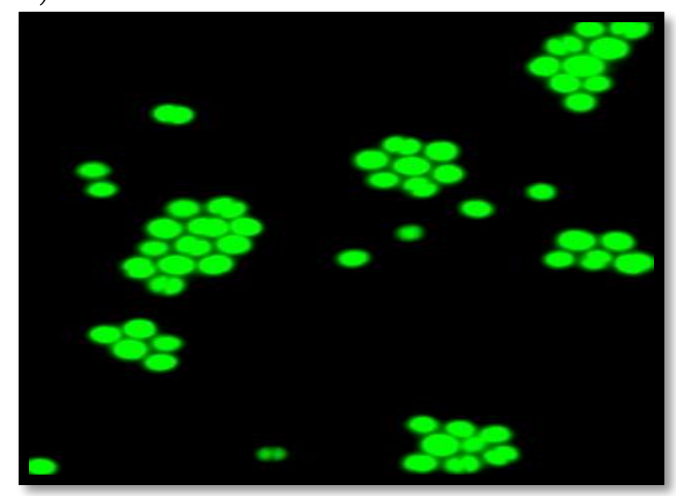

Fig. 8e: Coccus bacteria under Fluorescence Microscopy (FM)

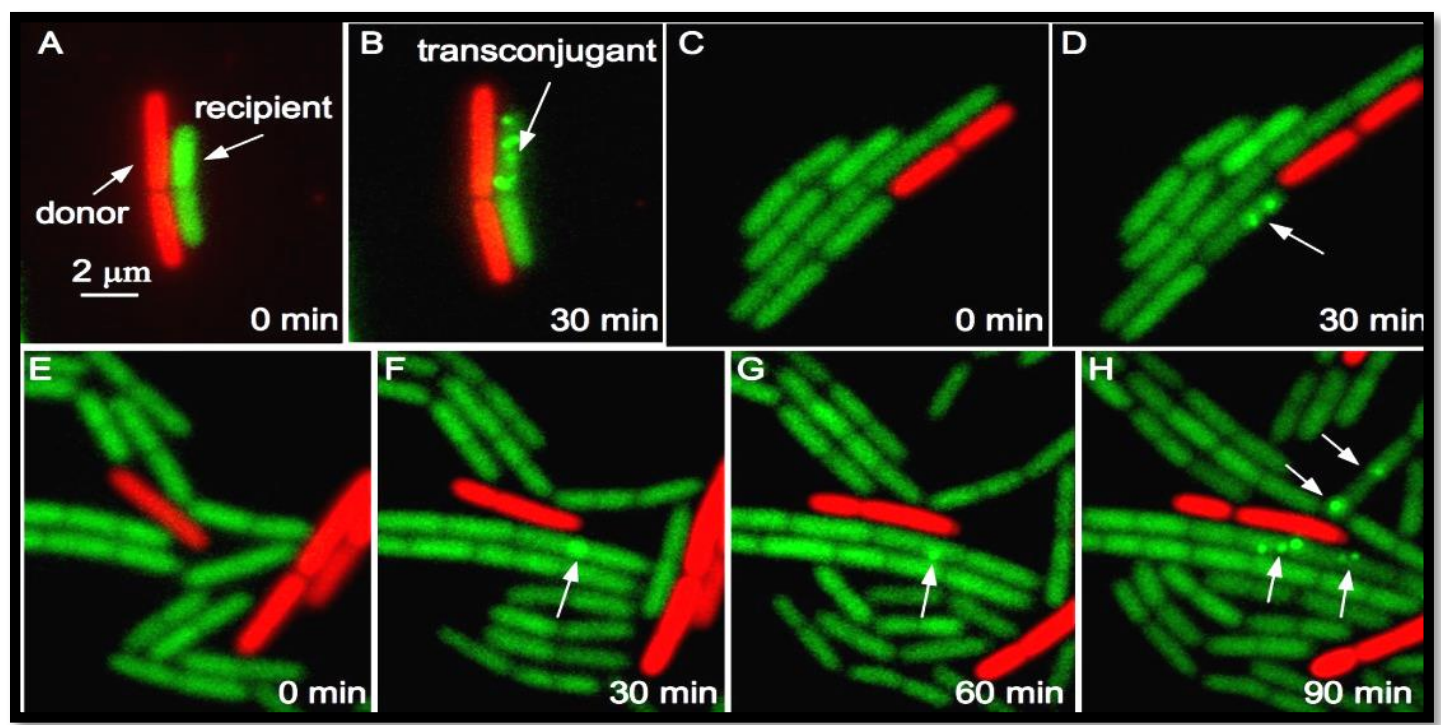

Fig. 8f: Different chromosomal stages under Fluorescence Microscopy (FM)

Polarized Light Microscope uses plane-polarised light to analyse the molecular structures that are birefringent i.e. structures that have two different refractive indices at right angles to one another (e.g. cellulose microfibrils). This type of microscope is equipped with a polarizer, positioned in the light path somewhere before the specimen, and an analyser i.e. a second polarizer which is placed in the optical pathway after the objective rear aperture (Fig. 9). When the plane-polarized light falls on a birefringent (or doubly-refracting) specimen it splits into two individual wave components that are each polarized in mutually perpendicular planes and become out of phase. They then pass through the analyzer where they are recombined with constructive and destructive interference. 


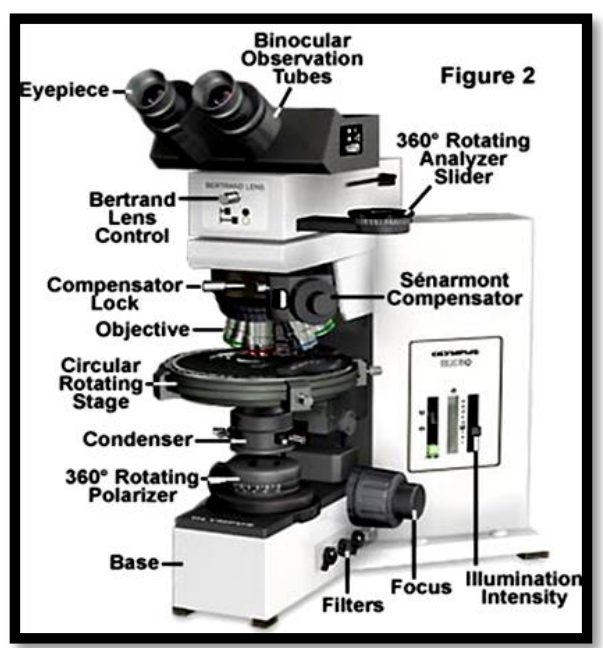

Fig. 9a: Modern Polarized Light Microscope (PLM).

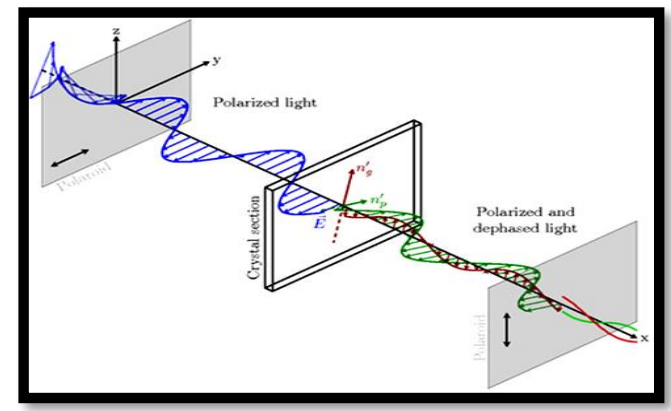

Fig.9b: Diagramatic representation of PolarizedLight Microscope [Light behavior in a petrographic microscope with light polarizing device. Only one inci wavelength is shown (monochromatic light). The magnetic field, perpendicular to the electric one, is not drawn.]
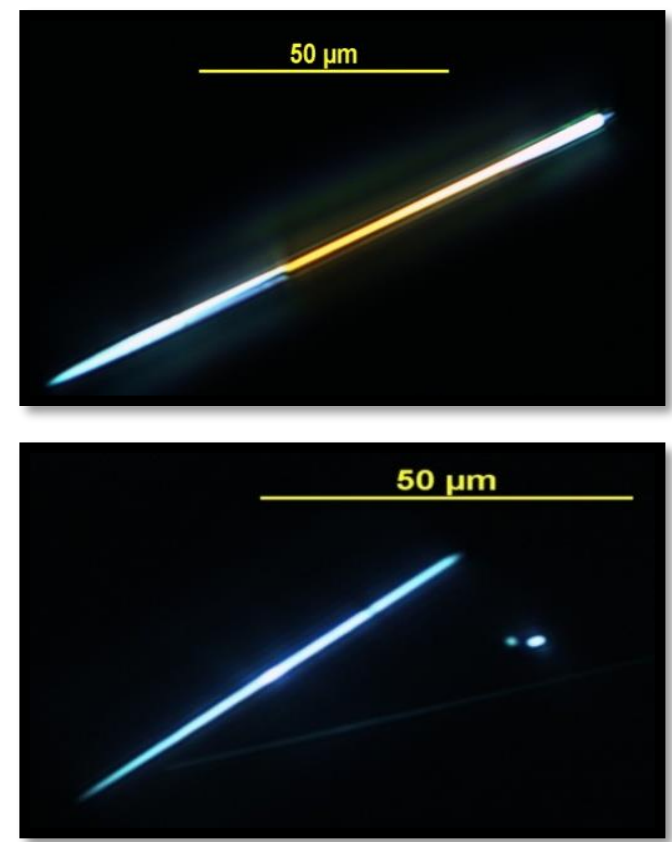

Fig. 9c \& d: Calcium Oxalate Crystals (COCs) under Polarized Light Mmicroscope (PLM).

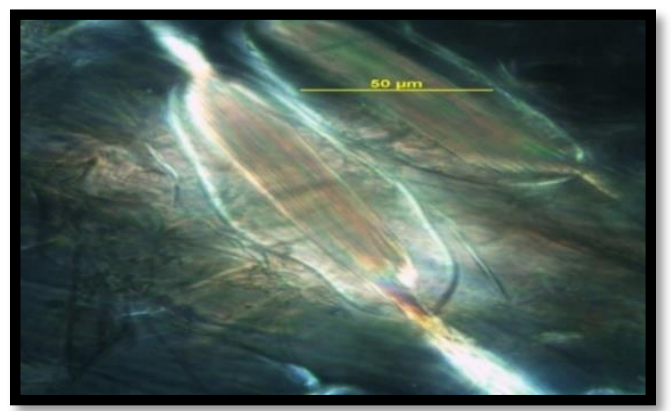

Fig. 9e: Idioblast with bunch of Calcium Oxalate Crystals (COCs) under Polarized Light Microscope (PLM).

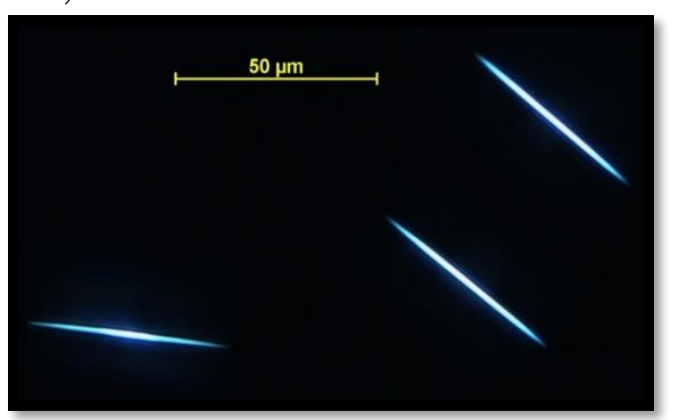

Fig. 9f: Calcium Oxalate Crystals under Polarized microscope.

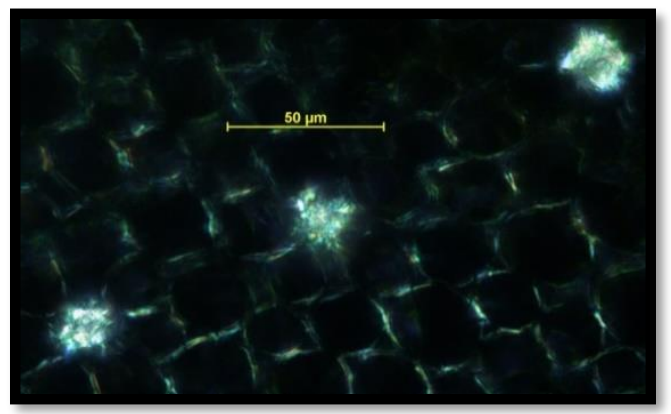

Fig. 9g. Calcium Oxalate Crystals (Druse) under Polarized Light Microscope.

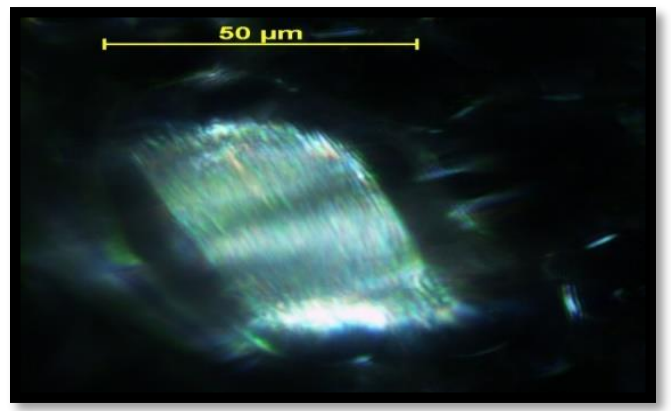

Fig. 9h: A bunch of Calcium Oxalate Crystals under Polarized microscope. 


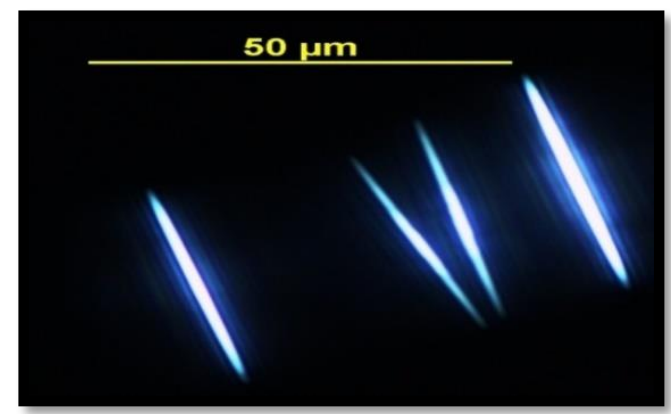

Fig. 9i: Calcium Oxalate Crystals under Polarized Light Microscope (PLM).

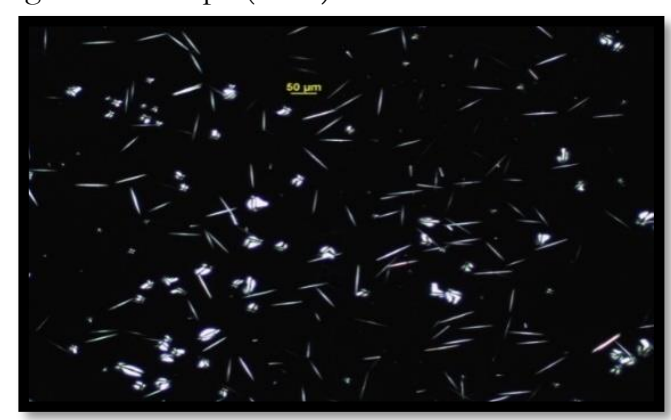

Fig. 9j: Calcium Oxalate Crystals with druse crystals under Polarized microscope.

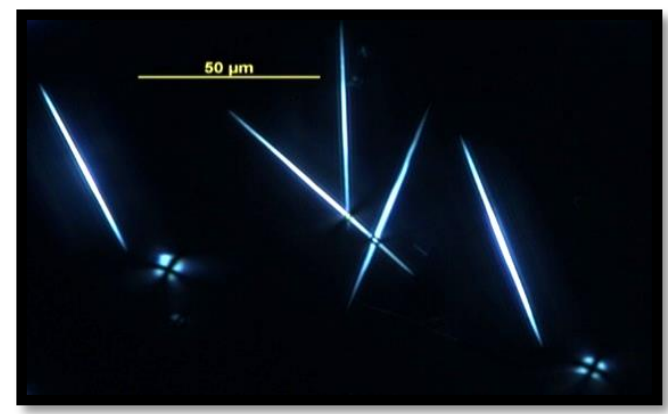

Fig. 9k: Calcium Oxalate Crystals with druse crystals under Polarized microscope.

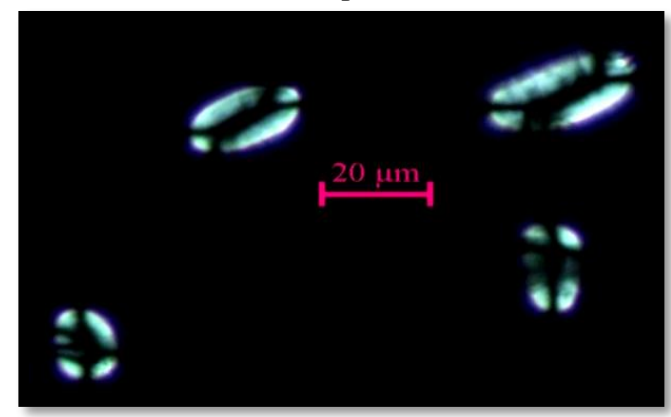

Fig. 91: A bunch of Calcium Oxalate Crystals under Polarized Light Microscope.

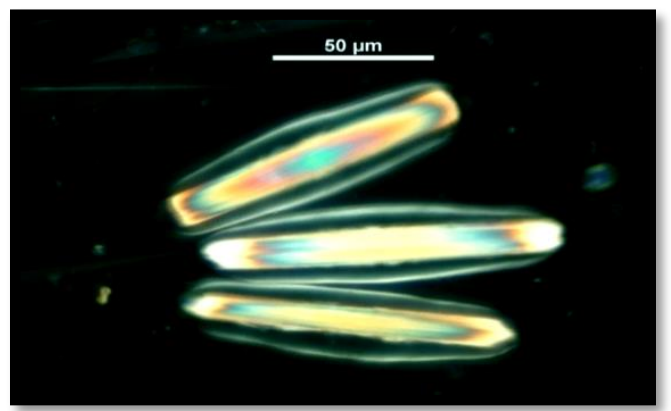

Fig. 9m: Three idioblast cells with Calcium Oxalate Crystals under Polarized Light Microscope (PLM).

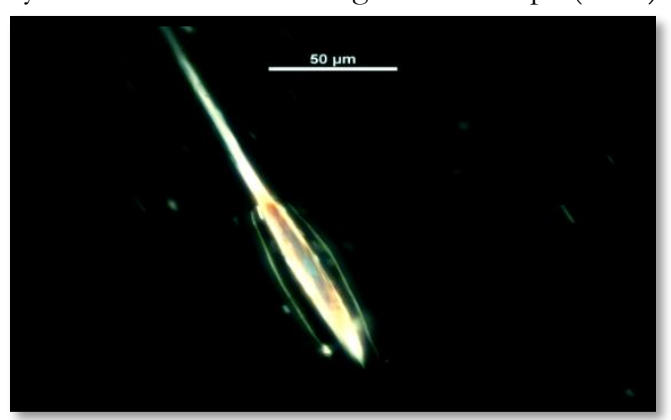

Fig. 9n: Ejection Calcium Oxalate Crystals Crystals found in Eichbornia crassipes under the Family Pontideriaceae.

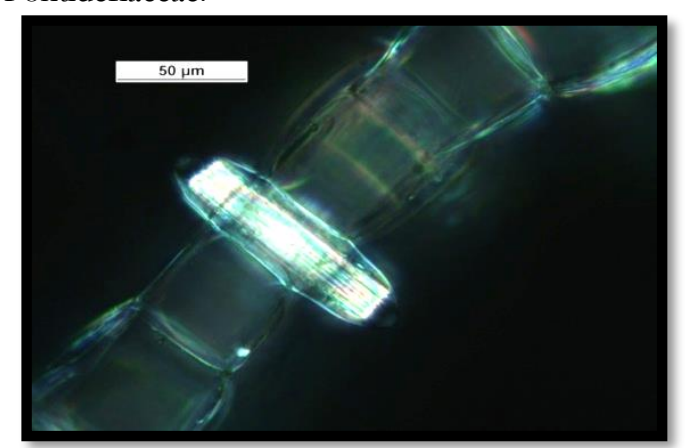

Fig. 9o: A typical type of Calcium Oxalatefrom edioblast cells under Polarizedmicroscope which is the identifying marker of thespecial plant species under Polarized Light Microscope.

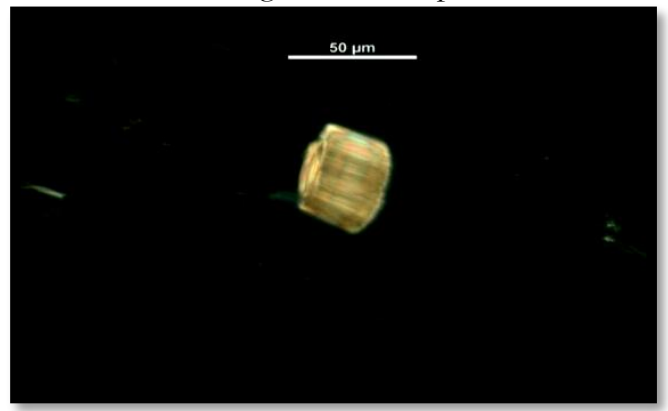

Fig. 9p: A typical type of starch grains of Phaseolus vulgaris under Polarizedmicroscope which is the identifying marker of thespecial plant species under Polarized Light Microscope. 


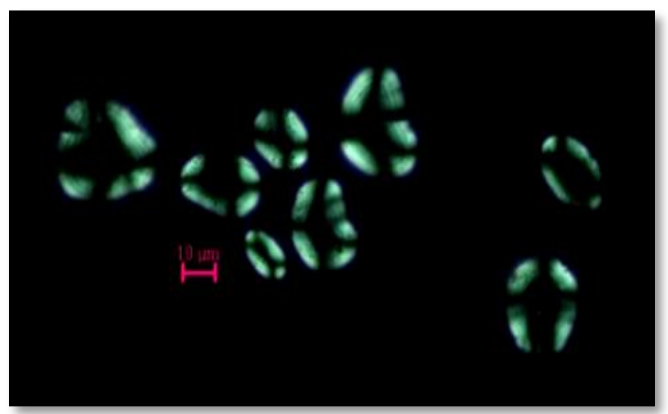

Fig. 9q: A typical type of starch grains of Pisum sativum under Polarizedmicroscope which is the identifying marker of thespecial plant species under Polarized Light Microscope.

To study the detailed structure of cells, Electron microscopes are widely used. They use electrons and not photons (light rays) for visualization. The first electron microscope was constructed in 1931. Electron microscopes have certain advantages over optical microscopes. The biggest advantage is that the resolving power of the electron microscope is much greater than that of the light microscope and hence produce higher magnification of up to 2 million times. Hence electron microscopes enables us to see many structures of even molecular size, such as proteins and nucleic acids which are normally not visible by optical microscopy.

There are two different types of electron microscopes:

- Transmission electron microscope

- Scanning electron microscope

To study the internal structure of cells, a Transmission electron microscope (TEM) is essential. In the TEM, electrons are used instead of light rays and electromagnets function as lenses, the whole system operating in a high vacuum (Fig. 10). This technique is used in characterizing internal cellular structures, study of fine details of objects such as bacterial flagella, locate chemical constituents of the cell, locate the position of enzymes within cells etc. The electron beam is passed through an extremely thin section of the specimen. Since electron beams do not penetrate very well, hence to see internal cell structure, even a single cell is too thick to be viewed directly. Thus special techniques are used to cut thin sections for the electron microscope. For example even a bacterial cell is cut into many very thin slices before examining under the electron microscope. They are then introduced into the instrument at a point between the magnetic condenser and the magnetic objective which is comparable to the stage of the light microscope. The magnified image is viewed on a fluorescent screen through an airtight window or recorded on a photographic plate by a camera built into the instrument. It gives a two-dimensional cross-section of the specimen. To obtain sufficient contrast, the preparations are treated with a special electron microscope stain such as osmic acid, permanganate, uranium or lanthanum salts, or lead which are composed of atoms of high atomic weight. Hence they scatter electrons well thus improving the contrast.

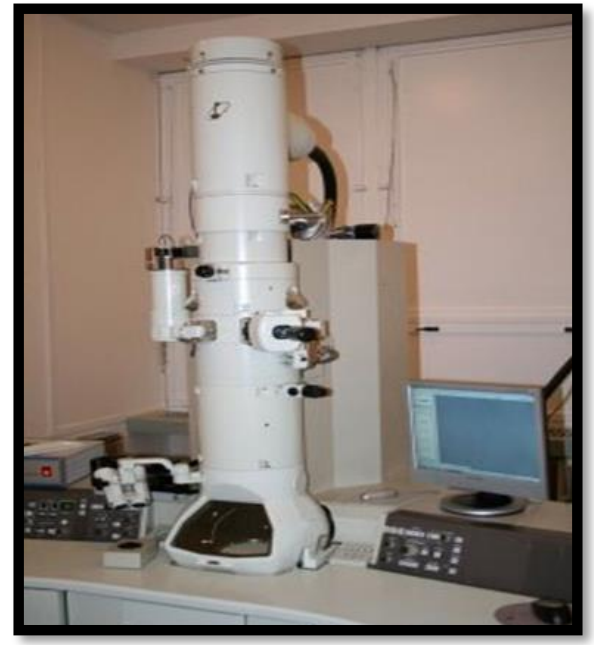

Fig. 10a: Transmission Electron Microscope (TEM)

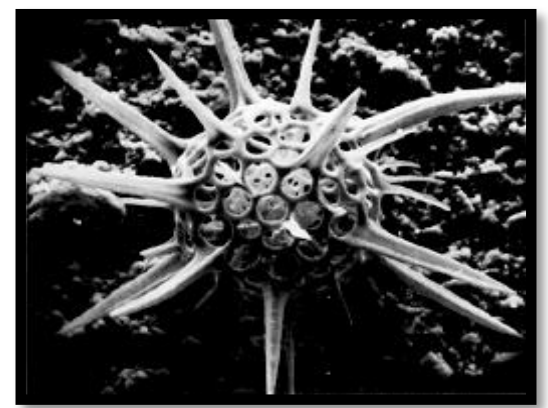

Fig. 10b: Pollen structure under Transmission Electron Microscope (TEM)

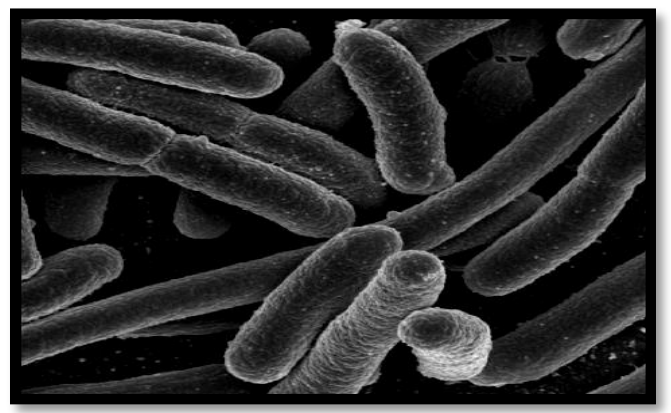

Fig. 10c: Rod shaped bacteria under Transmission Electron Microscope (TEM)

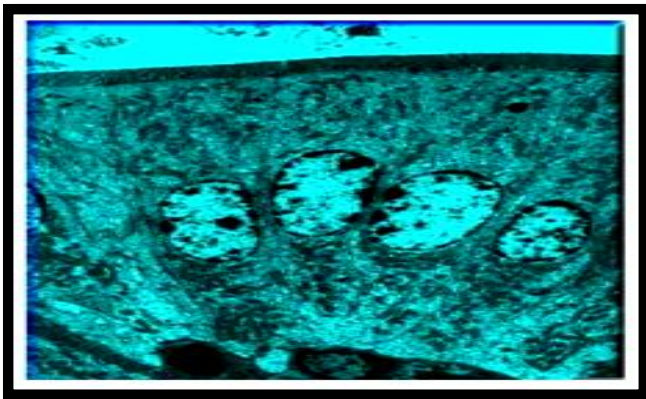

Fig. 10d. Transmission electron micrograph of epithelial cells from a rat small intestine scale bar $=5 \mathrm{~mm}$. 
Scanning Electron Microscopy is used to visualize the surface structure of the specimen. It can reveal the surface topography of a specimen with clarity and a depth of field which is not possible by any other method. A wide range of magnifications can be obtained with the SEM, from as low as $15 \mathrm{X}$ up to about $100,000 \mathrm{X}$, but only the surface of an object can be visualized. Although it lacks the resolving power which can be obtained in TEM, it has the advantage of giving a striking 3-dimentional picture. The specimen is coated with a thin film of a heavy metal such as gold and is then subjected to a narrow beam of electrons which rapidly scans the surface of the specimens (Fig. 11). This causes the release of a shower of secondary electrons and other types of radiations from the specimen surface. The secondary electrons are collected by a detector which generates an electronic signal that can be scanned to produce an image on a cathode ray tube in a manner similar to that of a television system.

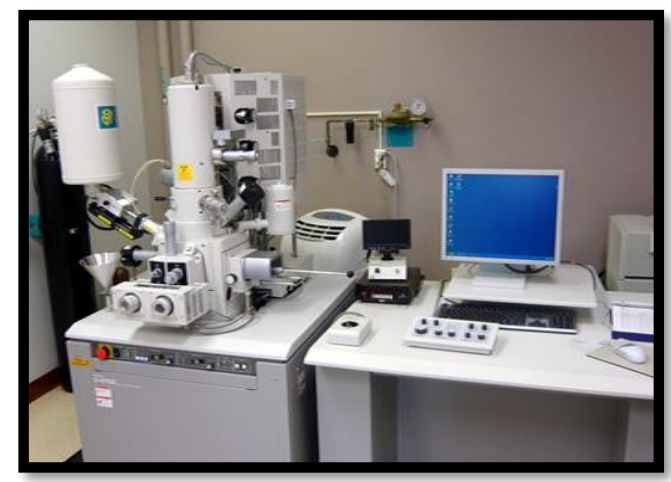

Fig. 11a: Scanning Electron Microscopy (SEM).

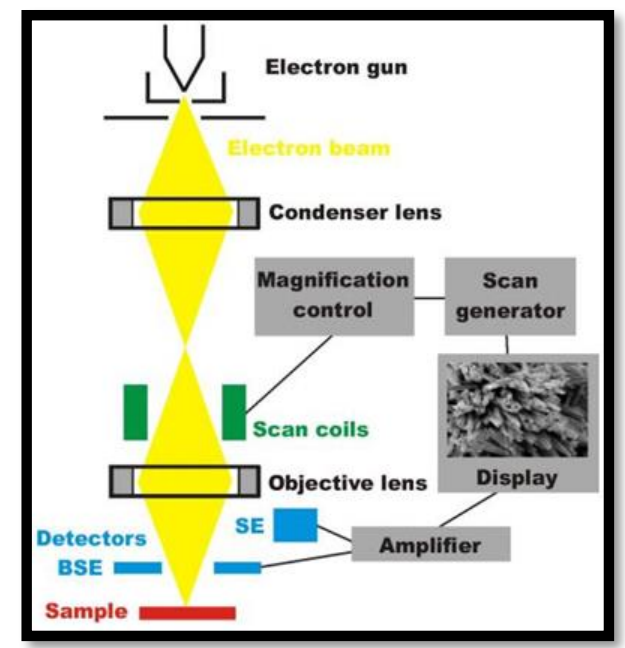

Fig. 11b: Diagrammatic representation of SEM

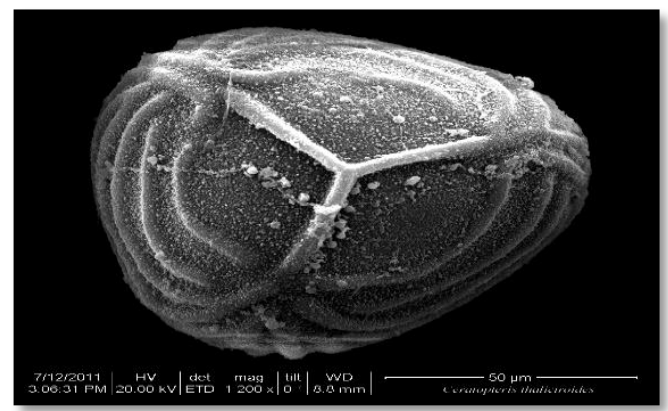

Fig. 11c: Scanning photograph of Ceratopteris sp. Spore

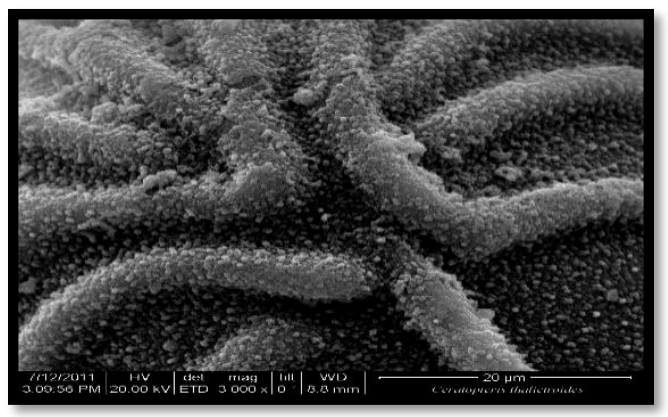

Fig. 11d: Close up view of Scanning photograph of Ceratopteris spore

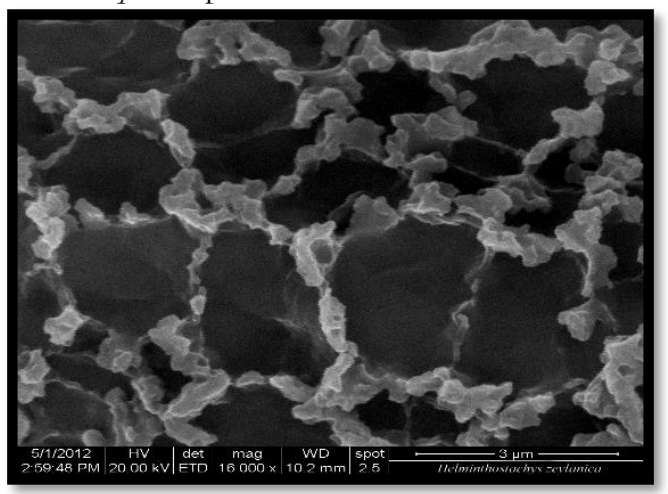

Fig. 11e: Scanning photograph of Helminthostecheis spore.

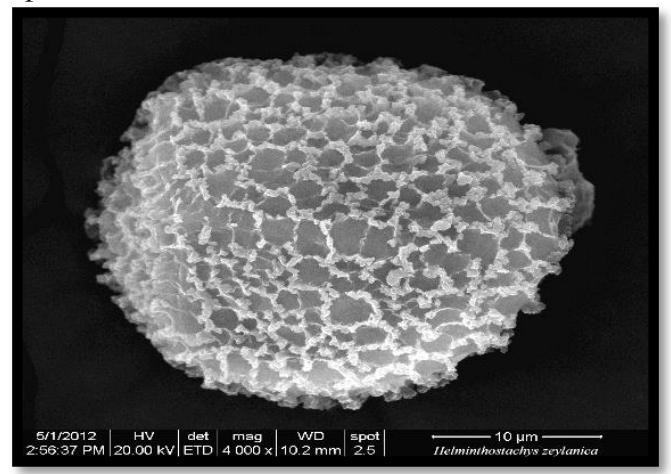

Fig. 11f: Close up view of Scanning photograph of Helminthostecheis spore. 

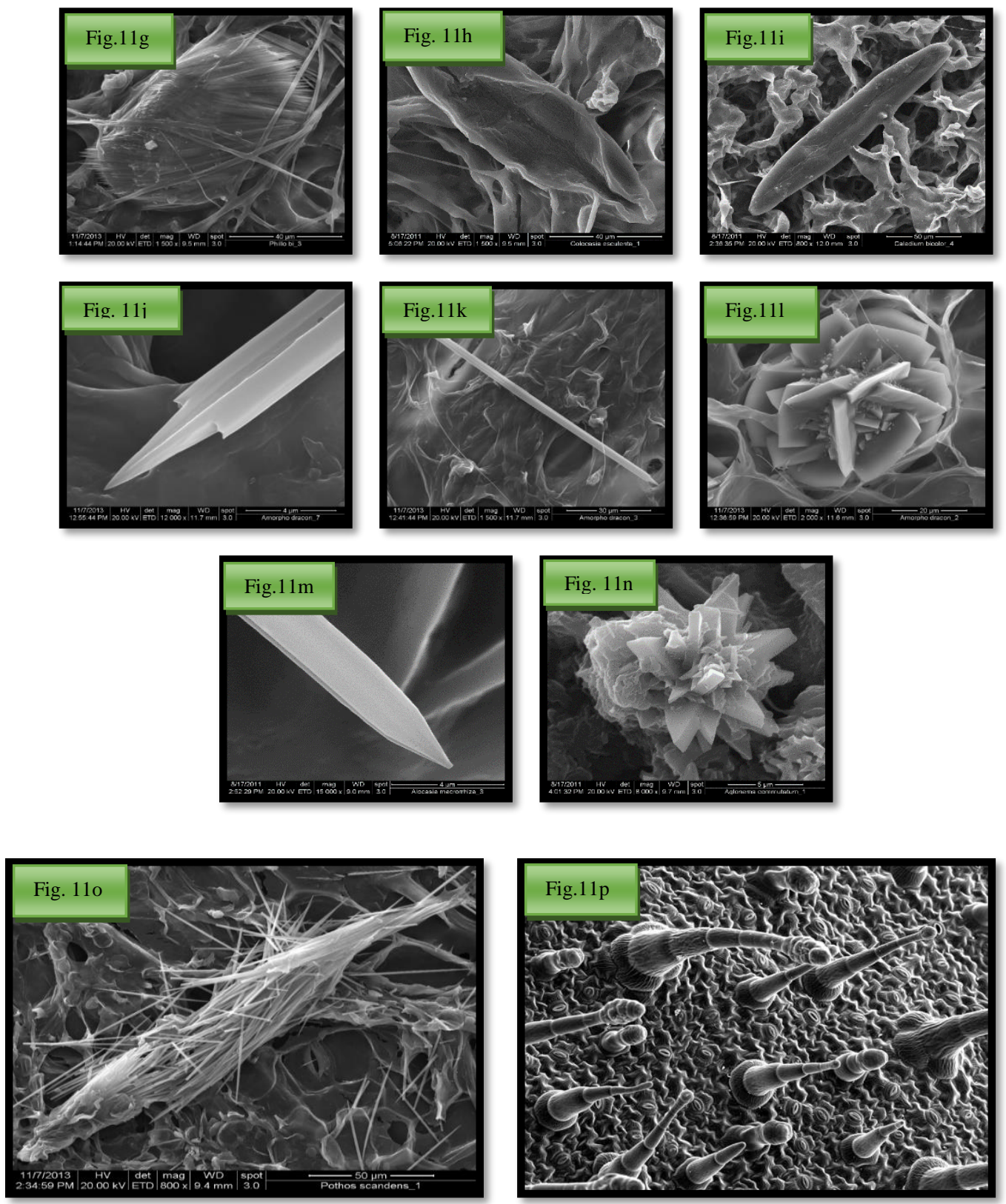

Fig. 11g-o: SEM photographs of calcium oxalate crystals, druce and prismatic crystals and Fig.11p: Leaf surface viewed by a scanning electron microscope (SEM).

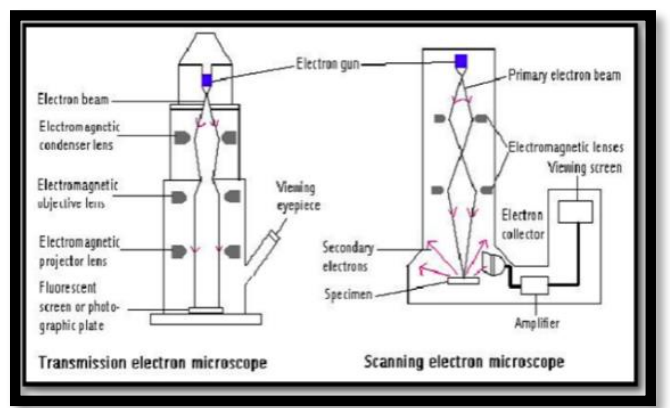

Fig.12. Comparative diagrammatic representation of TEM \& SEM

One of the major drawbacks of the different forms of light microscopy is that the images obtained are essentially two dimensional. This limitation can be overcome to some extent by using scanning electron microscope, but other forms of microscopy are also available now.

Atomic Force Microscopy (AFM) offers threedimensional imaging of biological structures. Unlike electron microscopes AFM allows living and hydrated specimens to be viewed which is not possible in the former. Although the images obtained appear similar to those of scanning electron microscopy, the AFM has the big advantage that specimen preparation is similar to that for light microscopy and does not require the fixatives or coatings as required in SEM. In atomic force microscopy, a tiny stylus is positioned extremely 
close to the specimens in such a way that weak repulsive atomic forces are established between the probe and the specimen. Hence as the specimen is scanned in both the horizontal and vertical directions, the stylus rides up and down the hills and valleys, constantly recording its interactions with the surface. This pattern is monitored by a series of detectors that feed the digital information into a computer that generates an image (Fig. 13).

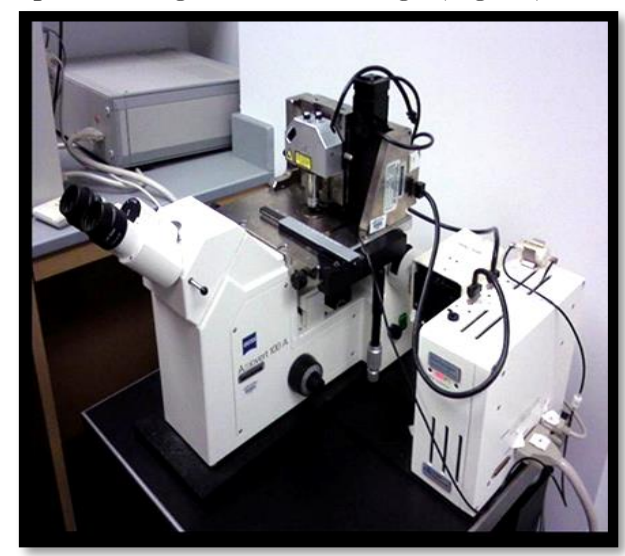

Fig. 13a: Atomic Force Microscopy (AFM)

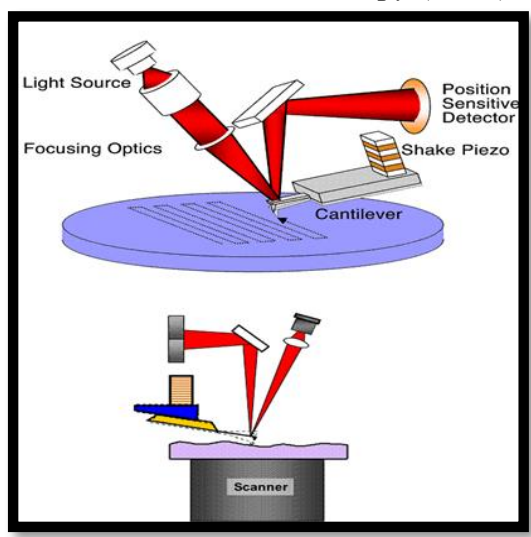

Fig. 13b: Diagrammatic representation of Atomic ForceMicroscopy (AFM).

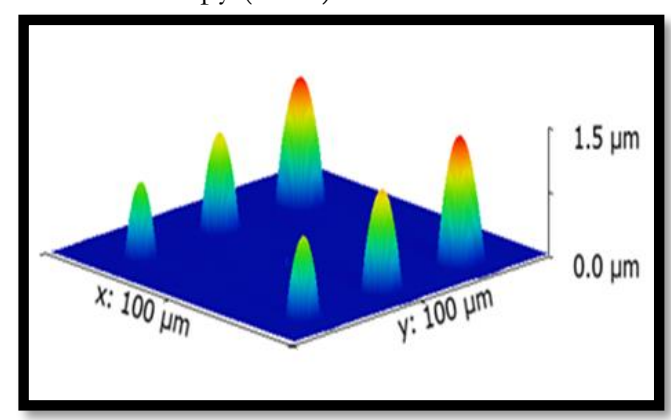

Fig. 13c: Photograph under Atomic Force Microscopy (AFM)

Confocal scanning laser microscopy (CSLM) is a computerized microscope which allows for the generation of three dimensional digital images of microorganisms and other biological specimens. It has a widespread use in microbial ecology, especially for identifying phylogenetically distinct populations of cells present in a microbial habitat. Unlike TEM, it is useful anywhere thick specimens need to be examined for their microbial content with depth. This microscope couples a laser light source to a light microscope (Fig. 14). The laser beam is bounced off a mirror which is then directed through a scanning device and then a pinhole which adjusts the plane of focus of the beam and allows it to fall on a particular vertical layer within a specimen. Thus only a single plane of the specimen is illuminated. The illumination intensity drops off rapidly above and below the plane of focus. Hence any stray light from other planes of focus is minimized. The cells in the various layers can be observed by adjusting the plane of focus of the laser beam. The microscope is equipped with computer software to assemble digital images for subsequent image processing. Thus, images obtained from different layers can be stored and then digitally overlaid to reconstruct a threedimensional image of the entire specimen.

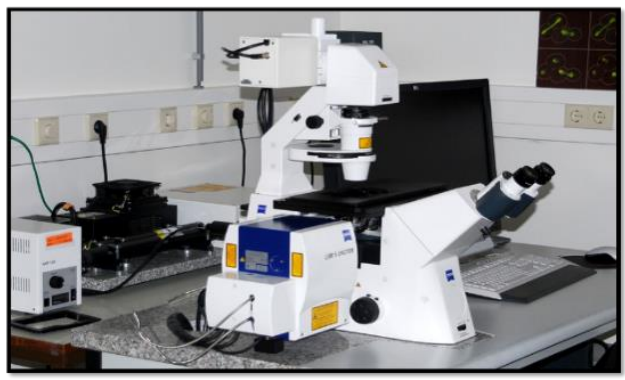

Fig. 14a: Confocal Scanning Laser Microscopy (CSLM).

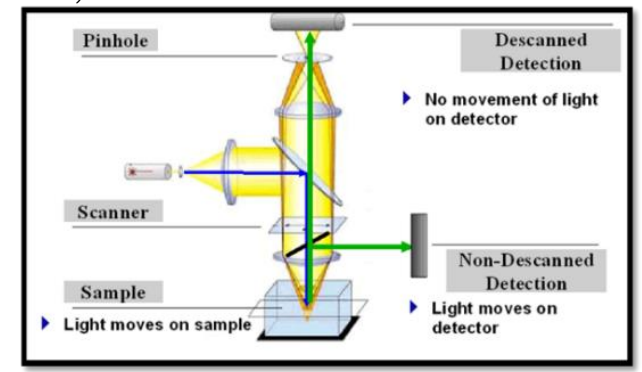

Fig.14b: Diagrammatic representation of Confocal Scanning Laser Microscopy (CSLM).

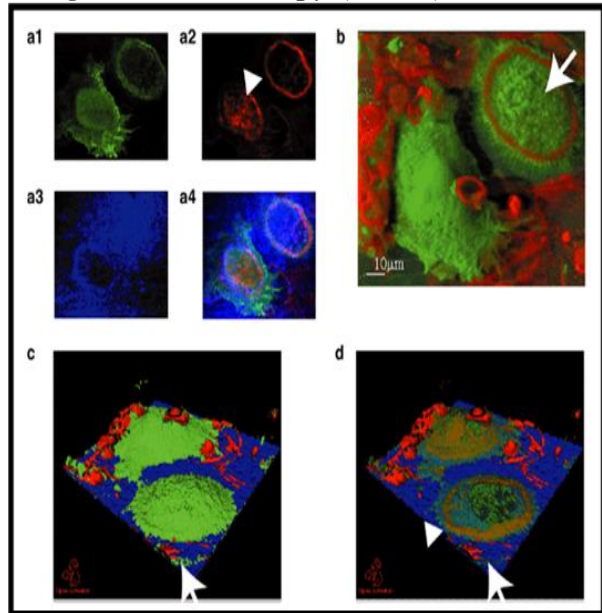

Fig.14c. Confocal Scanning Laser Microscopy of fixed and stained cells (CSLM). 


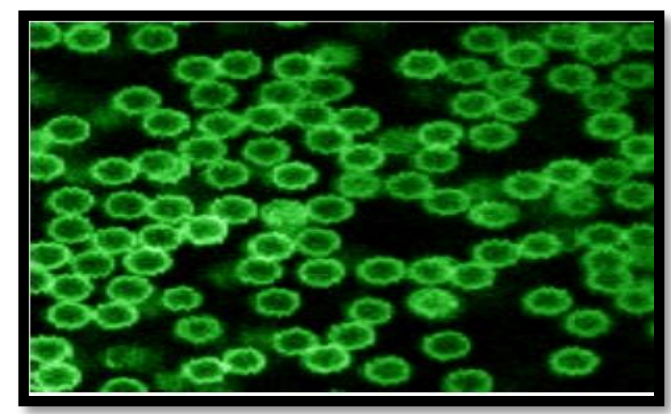

Fig. 14d: Photographs under Confocal Scanning Laser Microscopy (CLM).

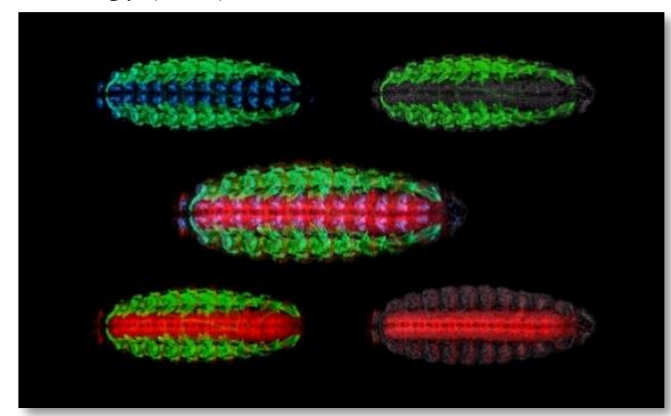

Fig.14e: Photographs under Confocal Scanning Laser Microscopy (CLM).

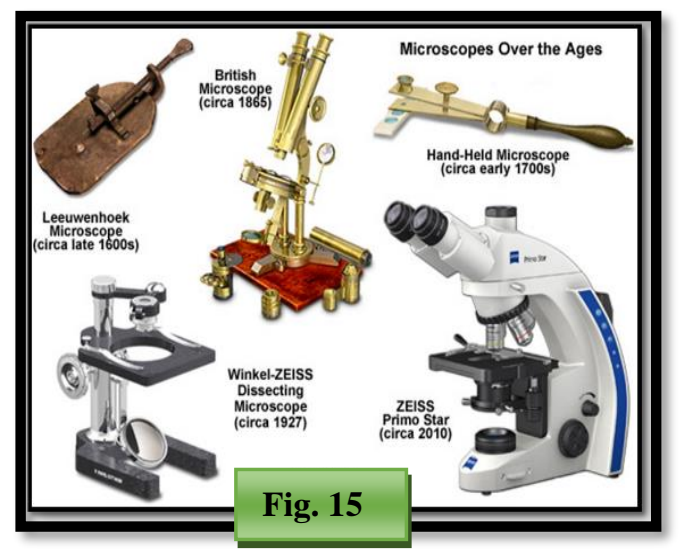

Fig. 15: Different types of Microscope

Thus, both electron and light microscopes are technical devices which have brought a revolution in modern science and are used for visualizing structures that are too small to see with the unaided eye, and both types have relevant areas of applications in biology and the materials sciences. Electron microscopy is expensive with high maintenance cost than light microscopes and needs elaborate sample preparation with the disadvantage that it does not allow to observe moving or coloured specimens, yet it has opened up a new vista enabling us to get a two dimensional or three-dimensional views of the specimens with minute details where light microscopy has failed. Thus Leeuwenhoek and Robert Hook to the modern Confocal scanning laser microscopyand Atomic Force Microscopy, there has been a saga of revolution, enabling man to see and discover the micro to ultra world which had evaded the eyes of ancient man.

Now the latest development in the microspical field which are very useful and easy to carry and handle for tiny scientist, school level scientist and field scientist to village level scientist called Foldcope microscope. A Foldscope is an optical microscope that can be assembled from simple components, including a sheet of paper and a lens. It was developed by Manu Prakash and designed to cost less than US $\$ 1$ to build. It is part of the "Fugal Science" movement which aims to make cheap and easy tools available for scientific use in the developing world.

The basic principle of using a small spherical lens held close to the eye dates back to Antonie van Leeuwenhoek (1632-1723), who was the first to see single-celled organisms using such a lens held in a device of his own design.

The Foldscope was developed by a team led by Manu Prakash, an assistant professor of bioengineering at the Stanford School of Medicine. The project was funded by several organisations including the Bill \& Melinda Gates Foundation, which gave a grant of US $\$ 100,000$ for research in November 2012.

The idea for creating a low-cost microscope came to Prakash in 2011 while he was at a field station in Thailand. He wanted to create an affordable microscope that would be versatile and sturdy enough to work in field conditions. He remarked that the station had a very expensive microscope but that everyone was afraid to use it because it was fragile and worth more than most people's salaries. He also wanted to create a device that people felt they had ownership of, which is part of the reason the Foldscope comes in a kit to be assembled. He developed the first prototype in 2014.

The Gordon and Betty Moore Foundation funded the "Ten Thousand Microscopes" project under which Prakash plans to give away 10,000 Foldscope kits to interested parties, including students for research. The projects eventually expanded to 50,000 Foldscope kits. Those who received the kits were encouraged to share their experiences using the microscope on a website, Foldscope Explore, so that Prakash's team could see how people could use the Foldscope. Examples of uses submitted by testers include a plant pathologist in Rwanda who used it to examine fungi on banana crops and Maasai children in Tanzania who used it to check cow feces for parasites. A Foldscope can be printed on a standard A4 sheet of paper and assembled in seven minutes. Prakash claims that the Foldscope can survive harsh conditions, including being thrown in water or dropped from a five-story building.

The goal of this project is not only to supply microscopes to those who would not otherwise have access to them but also to advance the general study of biomimicry. By encouraging thousands of volunteers to submit findings about the microorganisms they observe in their local environment, Prakash hopes to find more organisms that could provide clues about how to build new tools that take advantage of these organisms' natural abilities.

Department of Biotechnology Government of India (In October 2015) announced a program to make Foldscopes available across India at 80 approved colleges and programs. It will be used as a teaching tool for students in biology, chemistry and physics. After the pilot program, the Department hopes to work with Prakash to develop more low-cost science tools. Foldscope sets will also be produced and tested in Kenya and Uganda. Although the Foldscope has proven itself useful for a number of tasks, it is not currently adapted to be used as a medical 
diagnostic tool. When tested for diagnosing schistosomiasis in Ghana, for example, it was impossible to prevent contamination from urine samples because the Foldscope must be brought up to one's face to view. Jim Cybulski, a former graduate student of Prakash, is conducting research about using the Foldscope for diagnostic testing and is helping to develop a medical Foldscope that will cost $\$ 10$ and have a built-in projector allowing multiple people to view the magnification. A Foldscope is an optical microscope that can be assembled from a punched sheet of cardstock, a spherical glass lens, a light emitting diode and a diffuser panel, along with a watch battery that powers the LED. Once assembled, the Foldscope is about the size of a bookmark. The Foldscope weighs 8 grams and comes in a kit with multiple lenses that provide magnification from $140 \mathrm{X}$ to $2,000 \mathrm{X}$. The kit also includes magnets that can be stuck onto the Foldscope to attach it to a smartphone, allowing the user to take pictures of the magnification. The magnification power is enough to enable the spotting of organisms such as Leishmania donovani and Escherichia coli, as well as malarial parasites.

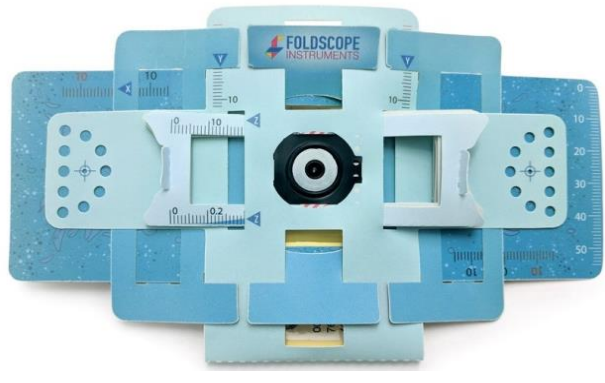

Fig. 16: Foldscope is the ultra-affordable, paper microscope that you assemble yourself. Designed to be extremely portable, durable, and to give optical quality similar to conventional research microscopes (magnification of 140X and 2-micron resolution), Foldscope brings hands-on microscopy to new places.

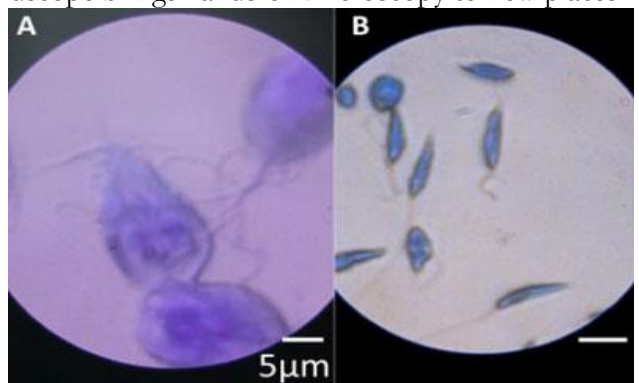

Fig. 17: Under Foldscope: The different tyopes of Microorganisms (Giardia (left) and Leishmania (right) as seen through the folding microscope). [CourtesyWikipedia).

\section{Acknowledgements}

We would like to thanks to our Research Scholars/Research Fellow (Ph.D. Work) in our Laboratory (Plant Taxonomy, Biosystematics and Molecular Taxonomy Laboratory, UGC-DRS-SAP-Phase I and DBT-BOOST-WB Laboratory and USIC, Vidyasagar University) and USIC-The University of Burdwan and USIC IIT, Kharagpur, West Bengal, India for their contributions in the form of different photographs (Light Microscope, Polarized Light Microscope, SEM, TEM, Stero Zoom Microscope etc.) for enriched our articles. We would like to thanks to Wekipedia google for latest information on Fold Scope Microscope with photographs.

\section{References}

1. Antoni van Leeuwenhoek; Samuel Hoole (1800). The Select Works of Antony van Leeuwenhoek, Containing His Microscopical Discoveries in Many of the Works of Nature.

2. Anderson, Douglas. Tiny Microscopes. Lens on Leeuwenhoek. Archived from the original on 2 May 2015. Retrieved 3 March 2016.

3. Dobell, Clifford (1923). "A Protozoological Bicentenary: Antony van Leeuwenhoek (1632-1723) and Louis Joblot (1645-1723)". Parasitology. 15: 308-19.

4. F. N. Egerton (1967). Leeuwenhoek as a founder of animal demography. Journal of the History of Biology. 1: $1-22$.

5. Mesler, Bill; Cleaves, H. James (7 December 2015). A Brief History of Creation: Science and the Search for the Origin of Life. W. W. Norton \& Company. p. 45. ISBN 978-0-393-24854-8.

6. Robert Hooke (1635-1703). Ucmp.berkeley.edu. Retrieved 13 June 2010.

7. Cybulski JS, Clements J, Prakash M (2014). Foldscope: origami-based paper microscope. PLOS ONE. 9 (6): e98781.

8. A Microscope to Save the World. The New Yorker. Retrieved 2015-12-22.

9. Coxworth, Ben (11 March 2014). Folding paper microscope could reduce deaths from malaria. Gizmag. Retrieved 13 March 2014.

10. Mathews, Lee (11 March 2014). Foldscope is a 50-cent paper microscope that magnifies up to 2000 times. Geek.com. Retrieved 13 March 2014.

11. Mukunth, Vasudev (12 March 2014). A disposable microscope for as little as $\$ 1$. The Hindu. Retrieved 13, March 2014.

12. Wakefield, Jane (11 March 2014). Ultra-cheap 'origami' microscope developed. BBC News. Retrieved 13 March 2014.

13. Newby, Kris (13 March 2014). Free DIY microscope kits to citizen scientists with inspiring project ideas". Scope. Retrieved 13 March 2014.

14. Foldscope paper microscope can diagnose malaria, costs 50 cent. CBC News. 13 March 2014. Retrieved 13 March 2014.

15. Origami microscopes for college students across India Nature India. Nature India. 2015.133.

\section{Cite this article as:}

Amal Kumar Mondal and Sanjukta Mondal Parui. The revolution in Microscopy - Simple to electron. Annals of Plant Sciences 7.5 (2018) pp. 2267-2281.

do http://dx.doi.org/10.21746/aps.2018.7.5.9 